\title{
O Hipólito, de Eurípides e o orgulho ateniense na parrésia
}

\author{
Manuel Fialho Silva
}
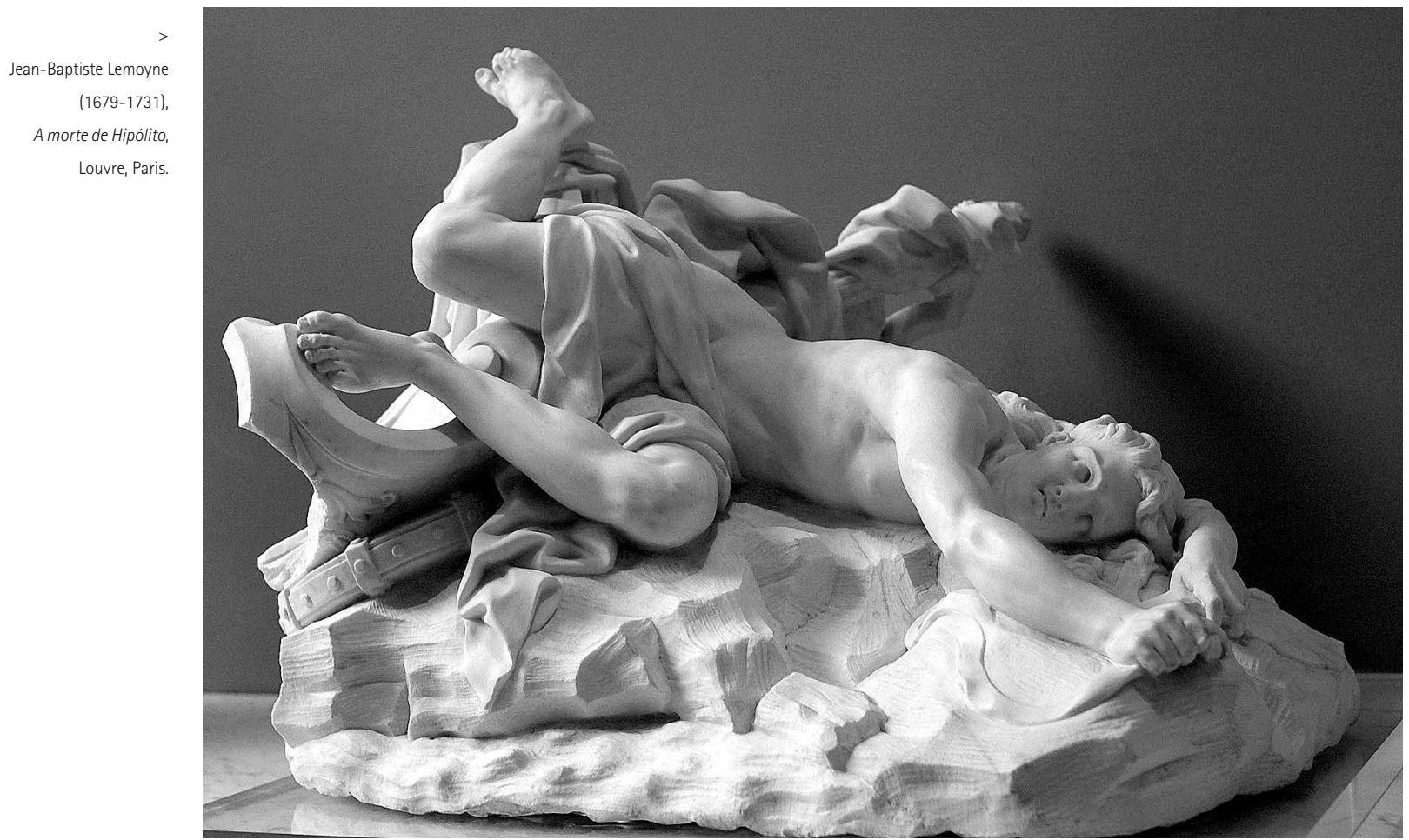

A parrésia é um conceito complexo, normalmente traduzido como "liberdade de expressão" ou "discurso franco", que se reinventa de acordo com o espaço e o tempo a que pertence. Neste artigo iremos referir-nos ao conceito de parrésia exclusivamente como era entendido na Atenas

cf. Euripides, do séc. V a.C., quando Euripides produzia as suas peças, As suplicantes, 438-441; Aristófanes, Acarnenses,

45 , e As mulheres que celebram as Tesmofórias,

379; Demóstenes,

Sobre a coroa, $169-73$

História da Guerra do Peloponeso, II, 47-53

Manuel Fialho Silva

é investigador do

Centro de Estudos

Clássicos da Faculdade

de Letras da

Universidade de lisbo focando mais especificamente a presença deste conceito no Hipólito de Eurípides, e sublinhando as intrincadas ligações entre parrésia, liberdade e honra.

Antes de abordar o tema da parrésia no teatro grego antigo, é crucial entender o orgulho e alta estima que os atenienses sentiam pela sua democracia. Na visão ateniense, o sistema democrático era o único que permitia verdadeira liberdade e autonomia aos cidadãos da polis. Devemos ter em conta que o ateniense do séc. $V$ considerava a possibilidade de tomar parte no exercício do poder uma componente indispensável da sua cidadania. Neste sentido a parrésia (que podemos entender aqui como "liberdade

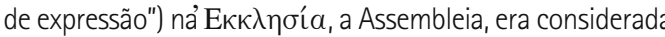
uma condição essencial para a execução da democracia. $\mathrm{Na}$ Assembleia, perante milhares de cidadãos, o Arauto

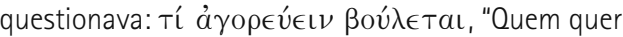

falar?" ${ }^{1}$. De facto, qualquer cidadão sabia que poderia realmente falar e contribuir activamente para as decisões tomadas na Assembleia. Esta capacidade de o cidadão poder afirmar a sua opinião livremente sobre os assuntos da polis constituía um verdadeiro orgulho para os atenienses, pois marcava a diferença entre a democracia e a monarquia e também relativamente a todos os outros sistemas políticos.

A necessidade de marcar a diferença e a superioridade da democracia está intimamente ligada com o momento histórico que Atenas vivia nesta época. Em 428 a.C., quando a tragédia Hipólito foi produzida, Atenas estava intensamente envolvida na segunda guerra do Peloponeso que tinha começado apenas três anos antes. Além disso, em 430, os atenienses sofriam tremendamente com a peste que Tucídides nos descreve ${ }^{2}$. Além de tudo isto, Péricles, o grande general ateniense, acabara de morrer no Outono de 429. Atenas perdia assim o seu general para sempre, embora seja importante notar que, algum tempo antes da morte de Péricles, os atenienses se tinham virado contra ele e contra a sua estratégia na guerra, apenas para mais tarde voltarem a mudar de direcção e o 


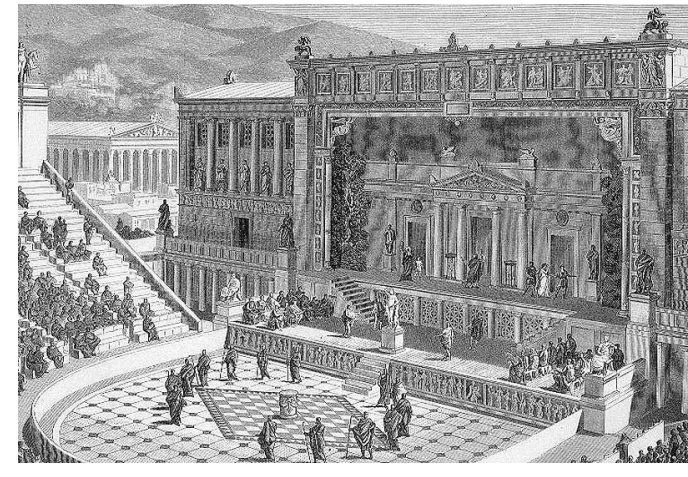

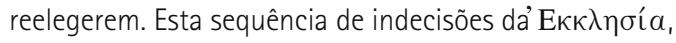
nomeadamente, sobre as suas escolhas politicas e militares, é muito relevante porque deixou marcas evidentes na peça de Euripides.

Deste modo, devemos referir que, em 428 a.C., os atenienses seriam, com certeza, cidadãos muito preocupados e teriam um profundo sentido de envolvimento e responsabilidade nas escolhas políticas e militares da polis. 0 clima político e social que Eurípides e a sua audiência viviam nesta altura é essencial para o nosso entendimento da tragédia e, especialmente, para a importância da menção da parrésia como uma caracteristica fundamental da "gloriosa Atenas" (v. 423).

A tragédia Hipólito de Eurípides é considerada uma obra excepcional, tanto pelos críticos actuais como pelos públicos do séc. $V$ a.C. Demonstrando este facto, no fim de Março de 428 a.C., esta tragédia recebeu o primeiro prémio nas Grandes Dionísias, o grande festival de drama celebrado em Atenas. Devemos notar que Euripides ganhou o primeiro prémio nas Grandes Dionisias apenas quatro vezes na sua longa carreira.

Vários aspectos desta obra contribuem para a sua excepcionalidade. Em primeiro lugar, é a única tragédia antiga conhecida que foi apresentada como sendo uma remodelação de uma versão anterior. Segundo, devemos referir a dificuldade em escolher que personagem encaixa melhor na concepção aristotélica do herói trágico, visto que Fedra, Hipólito e até a Ama concorrem para este estatuto.

0 que nos importa aqui referir é que Hipólito é uma tragédia baseada nos infortúnios causados pelo silêncio e pelo discurso erróneo das personagens centrais. Em suma, a sequência de eventos ocorre da seguinte forma: Fedra é descrita como uma mulher que tenta resistir a uma trágica paixão por Hipólito, filho de Teseu, seu marido. Ao tentar bloquear a sua paixão, ela é profundamente afectada pelo silêncio a que está submetida, e acaba por confessar os seus desejos à Ama, que os revela a Hipólito, um jovem que dedica a sua casta vida à adoração de Ártemis. Hipólito repudia as propostas da Ama, o que leva Fedra ao suicídio, momento em que deixa uma nota incriminando Hipólito de a ter violado. Teseu, ao tomar conhecimento do suicidio e da nota, amaldiçoa o seu filho, que mais tarde é fatalmente ferido por um touro que surge do mar, enviado por Posídon, a quem seu pai tinha pedido a fatal maldição. No êxodo, Ártemis revela a verdade a Teseu e Hipólito perdoa o seu pai.

Tal como foi notado por vários críticos, e mais notavelmente por Bernard Knox (1952: 3-31), o motor desta tragédia de Eurípides é alimentado pela escolha entre o silêncio e a produção de discurso pelas personagens. Esta situação oferece coesão à relação entre os quatro personagens centrais - Fedra, Hipólito, Ama e Teseu - pois contribui para a concepção da tragédia. Assim, na tragédia Hipólito estamos na presença de um drama sobre a palavra que é proferida no momento errado e o silêncio feito na pior ocasião.

Notemos que, no início da tragédia, o silêncio de Fedra sobre a sua paixão por Hipólito aparenta ser a única solução que permite uma morte honrosa para Fedra. Mas Fedra não respeita a sua primeira escolha e confessa a sua paixão à Ama. Neste ponto, devemos mencionar que a revelação da paixão de Fedra é a principal causa da sua ruína e é o primeiro incidente na sequência narrativa da tragédia. A Ama continua no mesmo caminho, escolhendo contar a Hipólito os desejos de Fedra. Estas duas acções marcam claramente o erro e o mal que pode advir da palavra dita no momento errado.

Hipólito, por sua vez, parece começar por querer relatar a seu pai a verdade, o que seria a escolha mais sensata, pois permitiria que continuasse vivo, mas acaba por preferir um silêncio fatal sobre as verdadeiras intenções de Fedra. Assim, no caso de Hipólito, o erro consiste em a personagem escolher um silêncio que se revela totalmente desastroso. Continuando este desfile de erros e equívocos, Teseu faz mais uma escolha infeliz, optando por amaldiçoar o seu filho e causando a sua morte através de palavras dirigidas ao alvo errado.

Apesar de todas estas escolhas erróneas, devemos referir que a tragédia termina com um final muito curioso, em que se prova que uma acção errada não condena para sempre quem a pratica e que, se forem tomadas as escolhas acertadas, este é perdoado, tal como Hipólito perdoa o seu pai.
Reconstituição do Teatro de Dioniso em Atenas. Fonte: Joseph Kürschner (editor): Pierers Konversationslexikon Encyclopedia, 1891. 
Depois de termos referido os momentos chave da tragédia e a sua relação com o discurso e o silêncio, foquemos a nossa atenção em alguns versos de Fedra quando esta confessa a sua paixão à Ama, mencionando a parrésia:

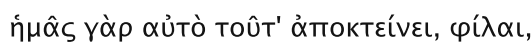

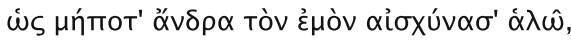

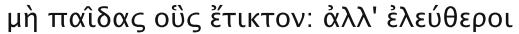

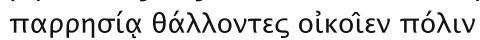

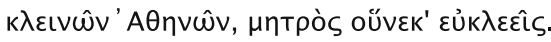

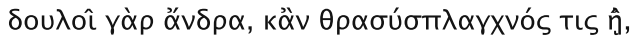

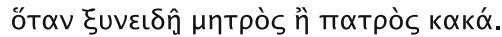

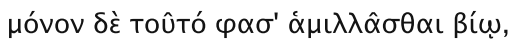

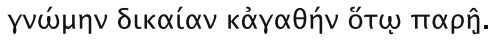

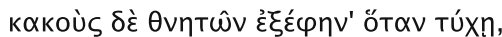

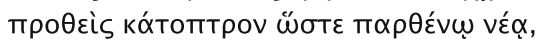

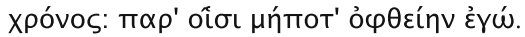
(Euripides, 1995: vv. 419-430)

\section{Amigas, o que me destrói é isto: que eu nunca seja} surpreendida a desonrar o meu marido ou os filhos que dei à luz. Que possam viver, florescentes e livres de dizer o que quiserem, na ilustre cidade de Atenas, prestigiados por causa da mãe. Mesmo que seja de espírito corajoso, é escravo o homem que vive na consciência das coisas vergonhosas praticadas pela mãe e pelo pai. Diz-se que na vida só concorre uma coisa: a posse de uma mente justa e boa. 0 tempo expõe à luz, sem data marcada, os que são perversos dentre os mortais, como que pondo um espelho à frente de uma jovem virgem. Que eu nunca me veja na sua companhia! (Euripides, 1996: vv. 419-430)

Fedra refere os seus filhos no último momento da sua confissão velada, falando directamente para o Coro, e expondo o seu argumento para o suicídio. 0 seu principal argumento apoia-se no facto de não poder ser

"surpreendida a desonrar o meu marido ou os filhos que dei à luz", tendo o cuidado, note-se, de não referir o filho de Teseu que ela não deu à luz, Hipólito, filho de Hipólita, rainha das Amazonas. Fedra deseja que os seus filhos "possam viver, florescentes e livres de dizer o que quiserem, na ilustre cidade de Atenas". Ora, de acordo com a mitologia grega, um dos seus filhos, Demofonte, irá de facto herdar o trono de Atenas. Interessa-nos sobretudo aqui notar a sua referência à liberdade de expressão, mappnбía,

intimamente ligada à liberdade, num sentido mais alargado, dos seus filhos (vv. 421-422). Estes dois aspectos, parrésia e liberdade, marcam a diferença e superioridade da democracia, um aspecto que, tal como já referimos, era de extrema importância para todos os cidadãos atenienses, pois estavam em guerra com Esparta e os seus aliados. Atenas era, para os seus cidadãos, e Eurípides não era excepção, o único lugar onde verdadeira liberdade em geral, e liberdade de expressão em particular, poderiam ser uma realidade na vida da polis. De facto, Eurípides não foi o único dramaturgo que considerou o tema da parrésia pois a problemática da liberdade de expressão estava presente no teatro grego antigo, tal como o demonstram as tragédias de Ésquilo e as comédias de Aristófanes.

Se considerarmos que fazer parte da audiência de uma tragédia grega era "acima de tudo fazer o papel do cidadão democrático", seguindo Simon Goldhill (1997: 54), notamos que a parrésia tinha um papel essencial no drama ateniense, visto que era uma necessidade para os poetas, pois a parrésia escudava-os de serem perseguidos ou punidos, quer por individuos quer pela polis. Além disso, a parrésia era também um factor fundamental da democracia, porque permitia uma contribuição para o governo da polis por parte de qualquer cidadão que estivesse presente na Assembleia.

Michel Foucault, nas suas lições dedicadas à noção grega da parrésia, notou a importância da tragédia Hipólito de Eurípides para a compreensão do conceito grego de parrésia. Para o filósofo francês, o discurso de Fedra, anteriormente citado, demonstra uma "relação entre a falta da parrésia e a escravatura" (2001: 30). Isto porque, quando um cidadão estava consciente de desonra na sua família, a liberdade de expressão seria afectada pela vergonha, tornando a parrésia impraticável. Na verdade, a principal preocupação de Fedra parece ser a desonra que ficará eternamente associada ao seu nome, o que acaba por acontecer. A honra era uma das qualidades que o cidadão ideal deveria possuir, sendo também necessária quando alguém se dirigia à Assembleia, pois um cidadão sem honra não era ouvido e a sua opinião não teria qualquer valor para o demos. Além disso, sabemos que alguns crimes específicos desqualificavam os cidadãos do direito de falar na Assembleia, tal como bater nos seus pais, desertar, ou ser três vezes culpado de crimes de corrupção. É notório que estes crimes causavam uma ferida profunda na honra da pessoa e consequentemente inibiam o direito à parrésia.

Neste ponto devemos relembrar, mais uma vez, que os atenienses estavam então a viver os delicados anos da segunda guerra do Peloponeso. Para Eurípides, tal como 


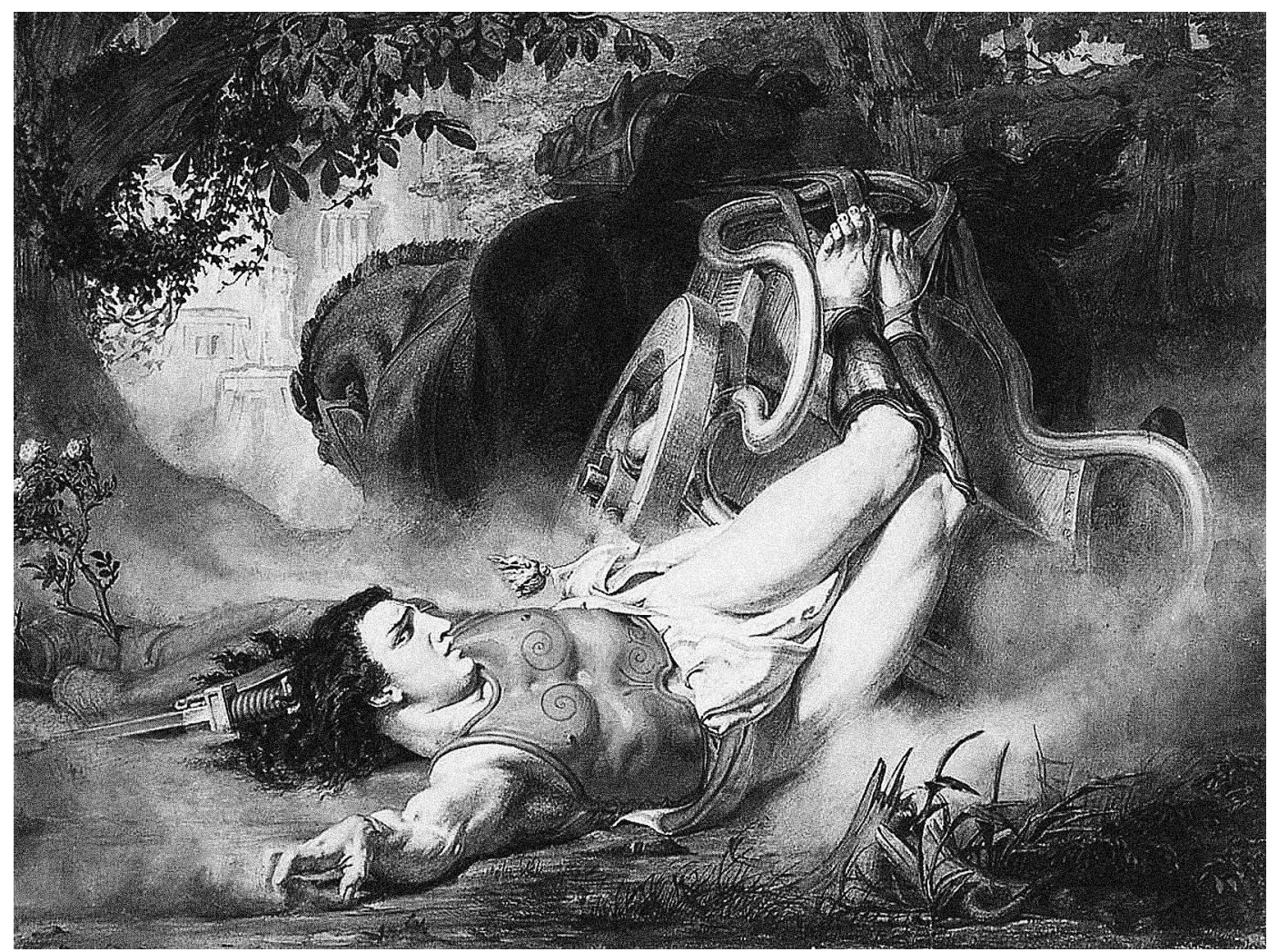

para qualquer ateniense, a glória e superioridade de Atenas em relação a Esparta apoiava-se, como já referimos, na diferença dos sistemas políticos, a democracia e a oligarquia, respectivamente. Outra questão relevante consiste no facto de que o tópico do silêncio e do discurso era de grande interesse para qualquer cidadão do demos, pois este deveria saber qual a altura certa para se dirigir à Assembleia e quando não o deveria fazer. Tal como na tragédia, decisões erradas poderiam ocorrer, como ocorriam de facto, no governo da polis, mas estas deveriam ser minoradas e controladas, sendo a parrésia uma arma muito eficaz para expor as decisões erradas.

Notemos também que, para os antigos gregos, neste caso os atenienses, a "liberdade de expressão", em relação ao conceito actual nas democracias ocidentais, não tinha o mesmo sentido, pois não significava apenas a possibilidade de se poder dizer tudo o que se pretende. Para um ateniense do séc. $V$ a.C., a parrésia implicava uma parcela de responsabilidade que actualmente não reconhecemos no nosso conceito, sobretudo porque o cidadão podia dizer tudo o queria na Assembleia, mas a sua honra e o seu estatuto estavam realmente em jogo quando ele se dirigia ao demos. Isto porque as decisões que a polis tomava sob o seu conselho eram realmente da sua responsabilidade. Por outras palavras, se acontecesse algo de mau para a cidade, a pessoa que tinha direccionado a polis em determinada escolha era responsável por essa escolha e era realmente punido por esse facto.

A escolha entre o silêncio e o discurso, tópico tão bem problematizado pelas personagens do Hipólito de Euripides, era um problema real para a polis. Tal como já referimos, decisões apressadas ou irreflectidas eram por vezes tomadas na Assembleia, mas eram muitas vezes repensadas e refeitas, tal como aconteceu no caso do afastamento, e posterior retorno, de Péricles como general de Atenas.
De tudo isto podemos concluir que o tema da revelação através das palavras, presente no Hipólito de Eurípides, é relevante não apenas para o estudo da literatura, mas também muito significativo para o nosso entendimento do funcionamento da polis e das suas singulares instituições.

A escolha entre guerra e paz, entre decisões correctas e incorrectas, era responsabilidade dos mesmos cidadãos que participavam na Assembleia e no teatro de Dioniso, assistindo às escolhas erróneas de Fedra e Hipólito.

\section{Referências bibliográficas}

EURÍPIDES (1995), Children of Heracles, Hippolytus, Andromache, Hecuba

(Vol. 2), ed. and translated by David Kovacs, Cambridge, Harvard University Press.

EURÍPIDES (1996), Hipólito, trad. Frederico Lourenço, Lisboa, Edições Colibri. FOUCAULT, Michel (2001), Fearless Speech, Los Angeles, Semiotext. GOLDHILL, Simon (1997), "The audience of Athenian Tragedy" in The Cambridge Companion to Greek Tragedy, Cambridge, Cambridge University Press.

KNOX, Bernard (1952), "The Hippolytus of Euripides" Yale Classical Studies, 13, pp. 3-31

Todas as imagens foram recolhidas na internet sob a licença Creative Commons (www.wikipedia.com). 